\title{
Cooperativismo y defensa del consumidor: la identidad entre el espíritu cooperativo y el fundamento del derecho del consumidor
}

\author{
José Eduardo de Mirandaํ y Andréa Corrêa Lima² \\ Universidad Católica de Pelotas
}

Recibido: $\quad$ 12.04.11

Aceptado: 17.05 .11

Sumario: I. Consideraciones preliminares. II. La preocupación por el ser humano: la verdadera esencia del espíritu cooperativo. III. El fundamento del Derecho del Consumidor. IV. La compatibilidad entre el Cooperativismo y la defensa del consumidor. V. A título de ultimas reflexiones: los valores cooperativos como prerrogativa de las relaciones económicas del mercado. VI. Referencias bibliográficas.

Resumen: Más allá de demostrar que el Hombre es el valor soberano del quehacer cooperativo, y presenta el comienzo y fines del Cooperativismo, se va exponer, también, el fundamento del Derecho del Consumidor. Además, pretendiese establecer el cambio de valor que se ha incrustado en el ámbito de las relaciones jurídicas de consumo, de manera que se muestra fundamental el rescate y empleo un nuevo modelo de actuación, basado en la axiología cooperativa, como forma de otorgar prevalencia a la dignidad de la persona humana. rativo.

Palabras clave: Cooperativismo, Defensa del consumidor, Espíritu coope-

Abstract: Beyond showing that man is the sovereign value of cooperative endeavor and presents the beginning and end of Cooperatives, will present also the foundation of consumer law. It also aims to establish the change in value that is embedded in the sphere of legal relations of consumption, so fundamental to the rescue and shows a new model of job performance, based on the axiology cooperative as a way to provide prevalence the dignity of the human person.

Key words: Cooperatives, Consumer protection, Cooperative spirit.

1 Doctor em Derecho; Abogado parecerista, profesor e investigador de la Universidad Católica de Pelotas.

2 Doctoranda em Derecho; Abogada y profesora universitaria. 
Todos somos más deudores a los demás de lo que nos imaginamos.

Arizmediarrieta $^{3}$

\section{Consideraciones preliminares}

Nadie duda que las relaciones de consumo evolucionaran muy aceleradamente en los últimos tiempos. De sencillas operaciones de cambio de productos en el estado natural, llegase hoy a las modernas operaciones de compra, venta y prestación de servicios. Los bienes de consumo son producidos en serie, las relaciones de consumo pierden su aspecto subjetivo, dejan de lado la celebración directa y pasan a ser desarrolladas de manera impersonal. "La producción en masa y el consumo en masa genera la sociedad de masa, sofisticada y compleja» ${ }^{4}$.

De esta manera, la distribución de productos y la prestación de servicios ha cambiado los modelos de contratación, y nuevos instrumentos jurídicos son elaborados previa e únicamente por los proveedores, sin la participación de los consumidores ${ }^{5}$.

La pérdida de conciencia por el valor del Humano fallece al valor material de lo que uno tiene y el otro desea. En el afán del consumo sin control, de la venta a todo coste, las relaciones jurídicas de consumo otorgan preponderancia al negocio, y hacen del consumidor el agente endeble, sujeto a las reglas de un juego ni siempre justo, ni siempre saludable.

Necesario, entonces, el cambio del paradigma: fundamental el rescate del matiz axiológico del Cooperativismo para conferirse al Hombre el valor e importancia que tiene en el medio y sobre el medio.

\section{La preocupación por el ser humano: la verdadera esencia del espíritu cooperativo}

El predominio de la especie humana ha representado una de las más grandes transformaciones operadas en el desarrollo de la natu-

3 Arizmendiarrieta, José María: Pensamientos. Estella: Caja Laboral, 1983, p. 130.

4 Almeida, João Batista de: A proteção jurídica do consumidor. 7. a ed. São Paulo: Saraiva, 2009, p. 2.

5 Filho, Sérgio Cavalieri: Programa de direito do consumidor, São Paulo: Atlas, 2008 , p. 3. 
raleza, y esta transformación se consuma cuando el Hombre descubre su importancia delante del medio, la importancia del medio en donde habita, y, por supuesto, la importancia de aquellos que comparten del medio con él ${ }^{6}$. Es así que el Hombre abandona la individualidad y pasa a vivir de manera gregaria. La agrupación original y espontánea da paso a la formación de hordas o gens constituidas por grupos de algunas docenas de personas unidas por vínculos de sangre ${ }^{7}$. El conjunto de varias hordas forma el clan y la unión de estos conforman la tribu, que es una forma superior de organización de la sociedad primitiva ${ }^{8}$.

Bajo este aspecto comunitario, el sistema económico de la colectividad prehistórica, por así decir, tiene como objetivo principal la producción de los medios indispensables para la existencia de las hordas, clanes y tribus, y se desarrolla mediante el empleo de los instrumentos de producción primitivos y la ejecución de un trabajo colectivo, "sin que existiera la propiedad privada, la división de la sociedad en clases y la explotación del hombre por el hombre» ${ }^{9}$.

Al verificar los buenos resultados de la unión de esfuerzos para el alcance de objetivos comunes, el Hombre inicia naturalmente las bases del esfuerzo cooperativo consciente y sistemático, que evoluciona coherentemente de acuerdo a la comprensión racional y las invariables necesidades humanas. Analizando esta ocurrencia, Toennies esclarece que la unidad de varios hombres puede ser considerada de dos mane-

6 En la historia de la humanidad, «as culturas assumem variáveis que alteram com bastante rapidez, incomparavelmente mais rápidas do que as eventuais alterações biológicas do homem. As culturas se acumulam, se diversificam, se complexificam e se enriquecem. Ou então, também, desenvolvem-se, por motivos sociais, se extinguem ou não são extintas» (Ostrower, F.: Criatividade e processos de criação, Petrópolis: Vozes, 1978, p. 55).

7 Durante este período la sociedad se desarrolla bajo la huella del matriarcado, y la mujer desempeña el papel de jefe de las gens. Por entonces, las relaciones de parentesco son computadas por línea materna, debido a que la forma de vida promiscua y el asesinato de muchas niñas ha provocado una gran escasez del sexo femenino. Solo después, con el desarrollar de la era es que la sociedad da paso al patriarcado, en donde el varón asume el papel de jefe de la sociedad y el parentesco se va a computar por línea paterna.

8 Es importante decir que «as mais antigas formas de vida humana registradas pela Paleontología são os denominados homínidas ou homínideos: o Australopithecus (encontrado na África do Sul), Pithecantropus (ou Homem de Java); o Sinantropus (ou Homem de Pequim); o Paleontropus (Homens de Hidelberg e de Neandertal, encontrados na Alemanha) (sobre el tema ver en Gordon Childe, V.: A evolução cultural do homem. Rio de Janeiro: Zahar Editores, 1971, p. 21).

9 Academia de Ciencias de la URSS: Manual de Economía Política, Ciencias Económicas y Sociales. 3. ${ }^{a}$ ed., México D.F.: Grimaldo, 1968, pp. 24-28. 
ras distintas: o bien antepone a la pluralidad, o bien la pluralidad es antecedente y la unidad se produce por ella ${ }^{10}$. Por así decir, "es la naturaleza sensible; aquél es el modo de ser del organismo; éste representa el grado inorgánico. Allí la unidad es realidad, es la cosa en sí y para sí misma; aquí es el ideal, es decir, no existe sino en tanto que es concebida por el pensamiento humano que efectúa representación, y, por fin, la concepción de tal todo, sea o no sobre el fundamento de la sensación. Mas en tanto que las partes integran el todo, puede, y aun necesariamente debe, la unidad, ser considerada como su producto, aun cuando el compuesto haya sido obtenido por la fuerza, merced a la voluntad humana. La cooperación de las partes —en la misma dirección para un movimiento común- es en el último caso el fin, en el primero, al menos, consecuencia de la combinación» ${ }^{11}$.

Sea la unidad antepuesta o sucesora a la pluralidad, parece cierto que la unión sistematizada de esfuerzos empleada para el provecho absoluto de acciones conjuntas y propósitos comunes, ha servido para la solidificación de instituciones constituidas por obra de la inteligencia humana, de la invención del propio Hombre, del sentimiento y de los deseos innatos a la especie Humana. Ha sido de este modo que primero se han integrado los grupos de seres humanos vinculados por lazos consanguíneos, o bien por grupos de Hombres iluminados por intenciones y esfuerzos conjuntos de supervivencia. De esta manera, se pude decir que la «la cooperación como forma de trabajo conjunto probablemente se dio desde la aparición del Hombre, ya a nivel de economía doméstica, ya en una dimensión más amplia, cuando se inició la división del trabajo. Es de suponer que la cooperación en sus inicios no se dio sólo por causas económicas, sino que el Hombre en razón de su instinto gregario buscó a sus semejantes para expresar sus relaciones afectivas, para reproducirse, para defenderse de los peligros, y también para practicar los cultos religiosos, las competencias deportivas, etc. $\rangle^{12}$.

En este sentido, Borgadus sostiene que el Hombre, probablemente, «le deba más al efecto del principio de la cooperación que a cualquier otro, en su evolución biológica y social. No sólo esto, sino que, sin la función del principio de la cooperación, de la sociabilidad y de la ayuda mutua, el progreso de la vida orgánica, el mejoramiento

10 Toennies apud Wilburg, J.C.: Introducción al estudio de la teoría administrativa. México D.F.: Limusa, 1987, p. 50.

11 Wilburg (1987): pp. 50-61.

12 Ramírez Baracaldo, B.: Teoría y doctrina de la cooperación. Bogotá: Ciudec, 1989, p. 76. 
del organismo y el fortalecimiento de las especies resulta totalmente incomprensible» ${ }^{13}$. Tanto es así que ha sido en cooperativa vida tribal o social avanzada como nace el lenguaje, y luego la escritura, entonces sorprendentes medios de comunicar y de comulgar en propósitos comunes $^{14}$.

Aranzadi manifiesta que la cooperación «no sólo es una práctica antiquísima, sino una conducta que se observa en todas las épocas, hasta las más remotas de la historia humana. Se conocen en todas las latitudes y tiempos diversas formas primitivas de cooperación de carácter familiar, tribal, etc.» ${ }^{15}$. Además, es justo en "estas costumbres e instituciones y su persistencia contienen una enseñanza más general, ya que patentizan el instinto y la tradición de ayuda mutua, de acción común, de posesión y de gestión en común que se manifiestan en la conciencia y en la vida popular de todas las épocas y países. En efecto, no es nada extraño que haya sucedido, ya que el hombre es un ser intrínsecamente social. Aparte de las tendencias naturales a la sociabilidad, el hombre es un ser indigente, que no se basta a sí mismo, y se siente impelido a asociarse con los demás hombres para la defensa de sus derechos y a la satisfacción de sus necesidades» ${ }^{16}$.

Desde el momento que sufre la mutación morfológica que le imprime el aspecto efectivamente humano, la acción cooperativa se va gradualmente desarrollando en los diferentes niveles de la propia vida humana. En el principio surge como acciones reflejas, y posteriormente, de acuerdo a la complejidad, asume las características del instinto humano.

Es verdad que en el comienzo del proceso de evolución de la especie humana, a la cooperación corresponde la consecución de unos objetivos relacionados con la supervivencia de un grupo; pero también lo es que se va manifestar en los periodos posteriores de la evolución humana bajo tipos comportamentales significativos de superación, para los cuales la existencia de unos cuantos individuos queda organizada en un cuerpo de personas que se unen con el objetivo de ayudarse mutuamente, uno con los otros, y todos con los demás.

13 Borgadus, E.S.: Principios y problemas del cooperativismo, México D.F.: Libreros Mexicanos Unidos, 1964, p. 21.

14 Argueira Miranda, M.A.: Carácter revolucionario del cooperativismo, Buenos Aires: Intercoop Editora Cooperativa Limitada, 1965, p. 17.

15 Aranzadi, D.: El arte de ser empresario hoy: hombres y mujeres ante el reto de dirigir empresas cooperativas en el umbral del siglo XXI, Bilbao: Departamento de Trabajo y Seguridad Social del Gobierno Vasco-Federación de las Cooperativas de Trabajo Asociado de Euskadi-Universidad de Deusto, 1992, p. 258.

16 Ibíd., p. 258. 
Por tanto, se puede identificar la cooperación verdadera en el comportamiento de aquél que pasa interesarse por la vida de los demás, e intenta colaborar en el proceso de transformación del Hombre, como un todo: social, económico, afectivo, y cooperativo.

\section{El fundamento del Derecho del Consumidor}

Hoy por hoy nadie duda que el consumo sea un fenómeno intrínseco a propia supervivencia del hombre en el seno social. Toda la gente es consumidora: desde el nacimiento, hasta la muerte, el hombre es víctima del consumo imparable ${ }^{17}$.

Vista esta realidad, y partiéndose del principio de que la legislación de defensa del consumidor incide sobre las relaciones de consumo, se muestra importante señalar que, en cuanto bilaterales, las relaciones de consumo "establecen o pueden establecerse cuando en una punta esté alguien con la actividad de ofertar productos o servicios y, en otra, conste alguien sujeto a tales ofertas» ${ }^{18}$. Por así decir, las relaciones de consumo son efectivamente relaciones económicas que presentan, de un lado, el proveedor, y de otro, el consumidor, que buscan una aproximación jurídica cuya finalidad es la satisfacción de las necesidades o designios del consumidor, el destinatario final del bien o servicio objeto de la celebración ${ }^{19}$.

Lo cierto es que en todos los puntos del Globo, desde sus orígenes, el hombre, por inclinación de su naturaleza, busca su pleno desarrollo no sólo en el ejercicio de sus facultades intelectuales, sino también en las raíces económicas en el espacio vital necesario para absorber con seguridad el jugo que alimenta. En este sentido, Almarcha anota que «el hombre obtiene su pleno desarrollo cuando sus

17 Almeida subraya que «o consumo é parte indissociável do cotidiano do ser humano. É verdadeira a afirmação de que todos nós somos consumidores. Independente da classe social e da faixa de renda, consumimos desde o nascimento e em todos os períodos de nossa existência. Por motivos variados, que vão desde a necessidade de sobrevivência até o consumo por simples desejo, o consumo pelo consumo» (Almeida: 2009, p. 1).

18 Gama, Hélio Zaghetto: Curso de direito do consumidor. 3. ${ }^{a}$ ed. Rio de Janeiro: Forense, 2008, p. 32.

19 No se puede olvidar que el proveedor, de acuerdo con la legislación brasileña, «é toda a pessoa pública ou privada, nacional ou estrangeira, bem como os entes despersonalizados, que desenvolvem atividades de produção, montagem, criação, construção, transformação, importação, exportação, distribuição ou comercialização de produtos ou prestação de serviços» (cf. artículo 3 del Código Brasileño de Defensa del Consumidor). 
actividades tienen las raíces en espacio vital propio, o sea por objetos de propiedad propia. El ansia del hombre no se aquieta, como en el mundo animal y vegetal, por la satisfacción de la necesidad del momento, sino que además de la satisfacción de esta necesidad quiere, como ser inteligente, la seguridad posible de que sus necesidades y las de su familia serán también satisfechas a través del tiempo con bienes en pleno dominio, de los cuales pueda usar y a los cuales pueda hacer producir el jugo que nutre, sin más limitación que la de la ley y sin más intervención que su voluntad» 20

Ocurre, sin embargo, que a lo largo del desarrollo de la humanidad, "la masificación de la producción, del consumo y de la contratación ha dejado el consumidor en desventaja, pues, en la medida que el proveedor se ha fortalecido técnica y económicamente, el consumidor tuvo su poder de opción fragilizado, prácticamente eliminado» ${ }^{21}$. La industrialización y las nuevas técnicas de operacionalización de las relaciones económicas alejara el consumidor del proveedor, sometiéndole a celebraciones mecánicas, a través del comprometimiento obligacional firmado, una y otra vez, en contractos de adhesión, cuyas cláusulas y condiciones estaban previamente ajustadas por el proveedor, siempre a su favor y beneficio.

Es así que las relaciones económicas se muestran demasiadamente sin equilibrio, de manera que la igualdad contractual fallece ante la fuerza de los proveedores. El consumidor, por supuesto, se torna rehén de sus propias necesidades, haciéndose, en el ámbito de las relaciones jurídicas de consumo, vulnerable, sea por su desconocimiento técnico o científico (también de aspecto jurídico), sea por su propia condición económica ${ }^{22}$. De hecho, «el reconocimiento de que el consumidor estaba desprotegido en términos educacionales, informativos, materiales y legislativos determinó la necesidad de más atención para el problema» ${ }^{23}$.

Como establece Almeida, "el consenso internacional relativo a la vulnerabilidad del consumidor en el mercado de consumo representó un importante hecho para el surgimiento de la tutela en el nivel de

20 Almarcha, L.: La cooperación como sistema económico-social, Madrid: Obra Sindical de Cooperación, 1945, p. 12.

21 Filho: 2008, p. 7

22 Además, se puede decir que el consumidor es vulnerable técnica, científica y jurídicamente por que no conoce las especificidades del producto o servicio y tampoco domina las informaciones respecto a los derechos inherentes a la relación económica que celebra.

23 Almeida (2009): p. 4. 
cada país» ${ }^{24}$. De esta manera, la protección del consumidor y la búsqueda por el equilibrio e igualdad de las relaciones de consumo pasan a ser un reto para el Derecho, y la vulnerabilidad del consumidor constituye el fundamento del propio Derecho del Consumidor.

\section{La compatibilidad entre el Cooperativismo y la defensa del consumidor}

A partir del momento en que el Derecho reconoce la desigualdad en el seno de las relaciones jurídicas de consumo, y determina que el Derecho del Consumidor asegure la igualdad real entre las partes, en razón de la vulnerabilidad del consumidor delante del proveedor, la compatibilidad del Cooperativismo con la defensa del consumidor se muestra evidente cuando el Hombre se presenta como el objeto de existencia de uno y otro.

En este sentido, se puede decir que la defensa del consumidor, a ejemplo del propio Cooperativismo, tiene una gran preocupación por la realización plena del individuo, protegiendo el derecho de las gentes, las libertades individuales de las personas, su salud y seguridad, asegurando, portando, la defensa de la dignidad de la persona humana. La defensa del consumidor, como el Cooperativismo, se desarrolla sin cualquier especie de discriminación, y alcanza a todas las personas, independientemente de sus condiciones sociales o económicas.

Además, no se puede olvidar que, así como el Cooperativismo, el movimiento de defensa del consumidor empieza, también, a través de las luchas de grupos sociales contra las discriminaciones de raza, sexo, edad y status profesional que se ha desarrollado a finales del siglo XIX e inicio del Xx. La primera organización de defensa del consumidor conocida ha sido una asociación de abogados de New York, nacida para conferir mejores condiciones a los trabajadores del comercio. La New York Consumers League fue fundada en 1891, y tenía la finalidad de fiscalizar el cumplimento de las normas de los derechos de los trabajadores y el buen atendimiento de los consumidores ${ }^{25}$.

Como ha ocurrido con el Cooperativismo, la preocupación de la defensa del consumidor no se ha limitado únicamente al ajuste de las cuestiones relacionadas con los beneficios económicos de las personas, sino que también ha apuntado hacia un objetivo moral que, además

24 lbíd., p. 4.

25 Gama (2008): p. 22. 
de procurar una mejor relación humana entre los individuos que comparten una vida, asienta un valor de decencia global que es legítimo en todos los tiempos, puesto que sirve de herramienta capaz de vencer las diferencias espirituales, ideológicas y culturales, promoviendo, de este modo, un proceso de construcción de un mundo con una nueva moral y un mejor sistema de sociedad ${ }^{26}$.

La verdad es que este objetivo, de eficacia moral, que ha nacido oficialmente en el universo del Cooperativismo a partir de los estatutos de la Cooperativa de los Pioneros de Rochdale, representa el desplazamiento de la moral cooperativa a las reglas que rigen la conducción de las relaciones interpersonales, incluso en el ámbito re las relaciones jurídicas de consumo, y que están vinculados a acciones más positivas y justas ${ }^{27}$. Con este perfil, las cooperativas se han constituido en diferentes lugares y durante todas las épocas como formas de defensa y reacción de amplios sectores de la población mundial que, frente a la insatisfacción de una diversidad de necesidades socioeconómicas, y conscientes de su debilidad individual, han decidido articular sus esfuerzos y fortalecerse a través de la ayuda mutua y la acción común ${ }^{28}$.

Asimismo, no se puede olvidar que en el marco del XXXI Congreso de la Alianza Cooperativa Internacional, se reconoce que el Cooperativismo se muestra como la oportunidad de «ayudar en la armonización de intereses entre grupos de personas organizados como consumidores de bienes y servicios» 29 . En este sentido, se muestra fundamental destacar que las cooperativas «siempre han tenido presente la información al consumidor como un derecho y como una de las herramientas más poderosas con las que hacer frente a la decisión de compra, a la modificación de conductas tendentes a mejorar la posición del consumidor en el mercado y al consumo responsable» ${ }^{30}$.

26 Miranda, José Eduardo de: De la cooperación al cooperativismo: análisis de los valores y principios cooperativos como instrumento de regeneración de entornos debilitados, Tesis Doctoral. Bilbao: Universidad de Deusto, 2008, p. 196.

27 Kaplan de Drimer, A.: «Rol del cooperativismo en el próximo milenio», en Anuario de Estudios Cooperativos 1999. Bilbao: Universidad de Deusto, 1999, p. 370.

28 Thordarson, B.: «Un análisis global de la función de las cooperativas en el desarrollo económico y social», en Revista de la Cooperación Internacional, 20.2, ACl, 1987, p. 47.

$29 \mathrm{ACl}$. Declaración de la Alianza Cooperativa Internacional sobre la Identidad Cooperativa aprobada en Manchester, Vitoria-Gasteiz: Consejo Superior de Cooperativas de Euskadi, 1996, p. 35.

30 Ventosa, Ignasi Faura y Udina, Teresa: La actividad de las cooperativas de consumidores. Disponible en www.fundacioncajamar.com/mediterraneo/revista/me0609.pdf, acceso en 35 de junio de 2011. 
Por ello, la defensa del consumidor a partir del quehacer cooperativo, se basa en la aportación, al consumidor, de herramientas clave como son la información y la formación para que cada persona utilice sus juicios para la tomada de decisiones conscientes en el ámbito de su vida cotidiana, en la búsqueda constante de la satisfacción de sus necesidades de manera más favorable a su desarrollo personal y social.

\section{A título de últimas reflexiones: los valores cooperativos como prerrogativa de las relaciones económicas del mercado}

La Declaración de la $\mathrm{ACl}$ sobre la Identidad Cooperativa, que trata sobre los valores cooperativos, establece que las cooperativas están basadas en los valores de la autoayuda, la autorresponsabilidad, la democracia, la igualdad, la equidad y la solidaridad; y los socios cooperativos hacen suyos los valores éticos de la honestidad, la transparencia, la responsabilidad y la vocación sociales ${ }^{31}$. Los valores cooperativos reflejan los ideales trazados por los precursores del Cooperativismo, a través de las iniciativas que han apuntado a una cooperación que, además de solucionar las necesidades materiales del hombre, se ha preocupado de colaborar con su transformación moral. Los valores cooperativos representan la identidad en la forma como las cooperativas y los cooperativistas deben abordar los problemas con los que se enfrentan continuamente, en el ámbito interno de la estructura económicamente organizada, y en el externo, en la órbita de los intereses de la propia humanidad. Los valores cooperativos, por tanto, se muestran como el propio espíritu cooperativo; el motor que impulsa el Cooperativismo vinculado a normas éticas que posibilitan la cooperación entre hombre y de la sociedad bajo una concepción antropológica del hombre y de sus relaciones sociales ${ }^{32}$.

Aunque las intenciones honorables se muestren como la cuna de una educación fortalecida por principios sublimes que aguanten virtudes diversificadas, es sabido por todos que la codicia, la envidia, el egoísmo y el deseo de poder y de poseer son peculiaridades propias de la naturaleza humana ${ }^{33}$.

Al observar que el apetito por el dominio y por el beneficio personal acompaña el hombre desde que ha dado su primer paso por la tierra, Divar anota que «para el humano, el bien general solo parece

31 Miranda (2008): p. 235.

32 Aranzadi (1992) p. 264.

33 Divar, Javier: La alternativa cooperativa: una respuesta ante la crisis, Barcelona: Ceac, 1985, p. 15. 
ser bien en cuanto posible, comprensible, por extensión, de su propio bien ${ }^{34} »$. Esta lección, de indeleble sabiduría, refleja el modus operandi que establece el desarrollo de una y otra relación de consumo.

Los proveedores, en general, ansiosos únicamente por la ganancia y beneficios, olvidan la preocupación por el precio justo y equitativo, relegan la importancia de la calidad del producto, y no raras las veces desdoran el valor de la seguridad y de los derechos de los consumidores.

De este modo, parece perfecto que la cooperación sistematizada es un modelo esencial para fortalecer las actividades de mercado, un vez que tiene el designio de permitir el progreso, el bien-estar y la transformación del Hombre.

Por ello, se debe subrayar que el objetivo general de la cooperación sostiene las actividades empresariales sobre valores sociales y morales que elevan la vida Humana sobre cualquier interese de connotación exclusivamente material. Considerando que el canal que aproxima la autogestión y la solidaridad del entorno donde se encuentra inserida, la cooperativa presenta la premisa de que la felicidad Humana es la esencia de la producción y de la circulación de bienes y servicios. Con base en ello, se puede percibir que diferente de lo que ocurre con los socios de la sociedad empresaria-capitalista, los cooperados remiten el interés especulativo para planes posteriores, y buscan aproximar el quehacer cooperativo de las acciones volcadas al auxilio de cuestiones Humanas, sean las de aspecto social, económico, político o ambiental y de consumo.

Hoy por hoy, la autoayuda, la autorresponsabilidad, la democracia, igualdad, solidaridad, honestidad, transparencia, responsabilidad y vocación social corresponden también a los pilares y principios que reglamentan las relaciones jurídicas de consumo, y sirven de escudo contra eventuales daños a los consumidores, pues toda relación económica de mercado desarrollada bajo el manto de la cooperación tiende a ser justa, una vez que la moral cooperativa sostiene la búsqueda por la preeminencia del verdadero sentido de dignidad, y hace prevalecer el respeto a la persona humana.

\section{Referencias bibliográficas}

Academia de Ciencias de la URSS: Manual de Economía Política, Ciencias Econó-

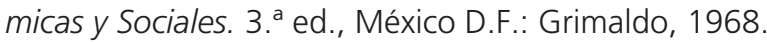

34 Ibíd., p. 15. 
ACl: Declaración de la Alianza Cooperativa Internacional sobre la Identidad Cooperativa aprobada en Manchester. Vitoria-Gasteiz: Consejo Superior de Cooperativas de Euskadi, 1996.

AlmarCha, L.: La cooperación como sistema económico-social. Madrid: Obra Sindical de Cooperación, 1945.

AlmeidA, João Batista de: A proteção jurídica do consumidor. 7. a ed. São Paulo: Saraiva, 2009.

Arizmendiarrieta, José María: Pensamientos. Estella: Caja Laboral, 1983.

ARANZADI, D.: El arte de ser empresario hoy: hombres y mujeres ante el reto de dirigir empresas cooperativas en el umbral del siglo XXI. Bilbao: Departamento de Trabajo y Seguridad Social del Gobierno Vasco-Federación de las Cooperativas de Trabajo Asociado de Euskadi-Universidad de Deusto, 1992.

Argueira Miranda, M.A.: Carácter revolucionario del cooperativismo. Buenos Aires: Intercoop Editora Cooperativa Limitada, 1965.

Borgadus, E.S.: Principios y problemas del cooperativismo. México D.F.: Libreros Mexicanos Unidos, 1964.

DIVAR, Javier: La alternativa cooperativa: una respuesta ante la crisis. Barcelona: Ceac, 1985.

FILHo, Sérgio Cavalieri: Programa de direito do consumidor. São Paulo: Atlas, 2008.

Gama, Hélio Zaghetto: Curso de direito do consumidor. 3. ${ }^{a}$ ed. Rio de Janeiro: Forense, 2008.

GoRdon CHILDE, V.: A evolução cultural do homem. Rio de Janeiro: Zahar Editores, 1971.

Kaplan de Drimer, A.: «Rol del cooperativismo en el próximo milenio», en Anuario de Estudios Cooperativos 1999. Bilbao: Universidad de Deusto, 1999.

MIRANDA, José Eduardo de: De la cooperación al cooperativismo: análisis de los valores y principios cooperativos como instrumento de regeneración de entornos debilitados. Tesis Doctoral. Bilbao: Universidad de Deusto, 2008.

Ostrower, F.: Criatividade e processos de criação. Petrópolis: Vozes, 1978.

Ramírez BARACALDO, B.: Teoría y doctrina de la cooperación. Bogotá: Ciudec, 1989, p.

TOENNIES apud WILBURG, J.C.: Introducción al estudio de la teoría administrativa. México D.F.: Limusa, 1987.

THORDARSON, B.: «Un análisis global de la función de las cooperativas en el desarrollo económico y social», en Revista de la Cooperación Internacional, 20,2, ACl, 1987.

VeNTOSA, Ignasi Faura y UdINA, Teresa: La actividad de las cooperativas de consumidores. Disponible en www.fundacioncajamar.com/mediterraneo/ revista/me0609.pdf, acceso en 35 de junio de 2011. 